\title{
ROLE OF THE TEACHER'S DISCUSSION SUBJECTS IN ENHANCING THE COMPETENCE OF ISLAMIC RELIGIOUS EDUCATION TEACHERS
}

\author{
1Saddam Husein, M.Pd.I., ${ }^{2}$ Sahrawi Saimima, M.Pd.I \\ 1,2,Dosen PAI FITK IAIN Ambon \\ saddamhusein@iainambon.ac.id
}

\begin{abstract}
In education the various problems faced by teachers is still often the case, came successive as the development of the times. Ranging from lack of mastery of the material in the learning process, a lack of understanding on curriculum applied, stuttering in operating technology, often active on social media with things which are not educating which led to the loss of authority as a teacher and others. This paper uses qualitative research methods. Reasons to use qualitative research methods because the author wanted to describe the naturally muswarah on the role of teachers of subjects in improving teacher competence. Conclusion in this paper, the role MGMP in improving teacher competence Education of Islam among them as a forum, a. teacher competency through increased competence of pedagogic, social competence, personality, competencies, competency and professional, $b$. intellectual capacity building of teachers, $\mathrm{c}$. as a discussion forum to find solutions in the face of challenges in the process of learning, $d$. increased sustainable profession forum.
\end{abstract}

\section{Keywords: Role MGMP, Competence Of Teachers PAI}

Abstrak Dalam dunia pendidikan berbagai masalah yang dihadapi oleh para guru masih kerap terjadi, datang silih berganti seiring perkembangan zaman. Mulai dari kurangnya penguasaan materi dalam proses pembelajaran, kurangnya pemahaman pada kurikulum yang diterapkan, gagap dalam mengoperasikan teknologi, sering aktifnya di sosial media dengan hal-hal yang tidak mendidik yang berujung dengan hilangnya wibawa sebagai seorang guru dll. Tulisan ini menggunakan metode penelitian kualitatif. Alasan digunakan metode penelitian kualitatif karena penulis hendak mendeskripsikan secara alami tentang peran muswarah guru mata pelajaran dalam meningkatkan kompetensi guru. Kesimpulan dalam tulisan ini, peran MGMP dalam meningkatkan kompetensi guru Pendidikan Agama Islam diantaranya sebagai forum, a. peningkatan kompetensi guru melalui kompetensi pedagogik, kompetensi kepribadian, kompetensi sosial, dan kompetensi professional, b. peningkatan kapasitas intelektual guru, c. sebagai forum musyawarah untuk menemukan solusi dalam menghadapi tantangan dalam proses pembelajaran, d. forum peningkatan profesi berkelanjutan.

\section{Kata Kunci: Peran MGMP, Kompetensi Guru PAI}

\section{Pendahuluan}

Persoalan dalam dunia pendidikan yang dihadapi oleh para guru masih kerap terjadi, datang silih berganti seiring perkembangan zaman. Mulai dari kurangnya penguasaan materi dalam proses pembelajaran, kurangnya pemahaman pada kurikulum yang diterapkan, gagap dalam mengoperasikan teknologi, sering aktifnya di sosial media dengan hal-hal yang tidak mendidik yang berujung dengan hilangnya wibawa sebagai seorang guru. Oleh karena itu, membutuhkan sebuah wadah yang dapat menghimpun para guru tersebut dalam upaya peningkatan kompetensi mereka. 
Adalah melalui forum Musyawarah Guru Mata Pelajaran atau MGMP. Forum MGMP merupakan suatu perkumpulan yang terdiri didalamnya adalah para guru satu mata pelajaran dari berbagai sekolah di suatu kota dengan tujuan saling melakukan tukar pendapat, pengalaman, komunikasi, belajar bersama dengan upaya mendapatkan perubahan dan pembaharuan dalam proses pembelajaran. Artinya, Muswarah Guru Mata Pelajaran merupakan salah satu sistem penataran guru dengan pola dari oleh, dan untuk guru (Muhammad Anwar, 2018). Saat ini hampir semua guru kelas maupun guru bidang studi di daerah kota maupun kabupaten sepakat mendirikan dan mengikuti KKG/MGMP. Organisasi tersebut telah berjalan dan memiliki program- program. Dalam perkembangan yang semakin pesat, guruguru telah sadar bahwa pengembangan diri dan wawasan pengetahuan sangat diperlukan sebagai bekal menjalankan tugasnya. Dengan demikian, tidak berbeda lagi kualitas guru di kotamadya maupun kabupaten (Husna, 2016).

\section{Metode Penelitian}

Tulisan ini menggunakan metode penelitian kualitatif. Alasan digunakan metode penelitian kualitatif, dikarenakan untuk mengetahui peran Forum Musyawarah Guru Mata Pelajaran dalam Meningkatkan Kompetensi Guru, penulis hendak merujuk pada Bogdan dan Taylor dalam (Maleong, 2001) menjelaskan penelitian kualitatif sebagai prosedur penelitian yang menghasilkan data deskripsi berupa kata-kata tertulis atau lisan dari orang-orang dan prilaku yang dapat diamati.

\section{Hasil}

Secara garis besar dapat dipahami, MGMP sangat berperan dalam meningkatkan kompetensi guru PAI. Banyak juga diantara para guru yang memiliki kelebihan dan kekurangan dalam penguasaan materi maupun aktualisasi proses pembelajaran. Agar MGMP dapat berkesinambungan dengan baik, maka kegiatan apapun yang dilaksanakan harus memberi makna dan nilai tambah bagi guru PAI yang terlibat dalam kegiatan, sehingga MGMP menjadi forum yang bermanfaat dan dibutuhkan oleh Guru PAI. Berikut bebrapa peran MGMP dalam meningkatkan kompetensi guru PAl yang dapat dikemukakan, meliputi:

a. Meningkatkan kompetensi guru melalui kompetensi pedagogik, kompetensi kepribadian, kompetensi sosial, dan kompetensi profesional

b. Peningkatan kapasitas intelektual guru

c. Sebagai forum musyawarah untuk menemukan solusi dalam menghadapi tantangan dalam proses pembelajaran

d. Forum peningkatan profesi berkelanjutan.

Dengan demikian dapat disimpulkan, peran MGMP dalam meningkatkan kompetensi guru PAI, dalam operasionalnya memiliki peran yang sangat efektif dalam peningkatan kompetensi guru, selain sebagai sosok atau panutan bagi para peserta didik di sekolah, guru juga memainkan peran yang sangat besar dalam menentukan tinggi atau rendahnya mutu pendidikan. Oleh karena itu, dengan 
seringnya mengikuti MGMP para guru akan mendapatkan perhatian khusus dalam proses pembaharuan pendidikan. Terutama dalam proses pembelajaran di dalam kelas.

\section{Pembahasan}

\section{Peran MGMP}

Musyawarah Guru Mata Pelajaran (MGMP) merupakan suatu wadah yang disediakan bagi para guru mata pelajaran sejenis untuk memecahkan berbagai persoalan yang dihadapi dalam upaya peningkatan kinerja guru (Firman, 2016). MGMP adalah suatu forum atau wadah kegiatan professional guru pada suatu jenis mata pelajaran di sanggar atau masing-masing sekolah yang terdiri dari dua unsur yaitu musyawarah dan guru mata pelajaran. Sementara guru mata pelajaran adalah guru SMP dan SMA Negeri atau Swasta yang mengasuh dan bertanggung jawab dalam mengelola mata pelajaran yang ditetapkan dalam kurikulum (Mintarsih, 2012). Kelompok kerja guru (KKG) dan MGMP adalah wadah pengembangan guru tingkat dasar, tingkat menengah dan tingkat atas. KKG dan MGMP merupakan organisasi guru non-struktural dan non-profit yang pengelolaannya dan pendanaannya dari, oleh dan untuk guru (Jejen Musfah, 2015).

Departemen Pendidikan Nasional merumuskan tujuan penyelenggaraan MGMP yaitu, Pertama, Memperluas wawasan dan pengetahuan guru dalam berbagai hal, khususnya penguasaan substansi materi pembelajaran, penyusunan silabus, penyusunan bahan-bahan pembelajaran, strategi pembelajaran, metode

pembelajaran, memaksimalkan pemakaian sarana/prasarana belajar, memanfaatkan sumber belajar, dsb. Kedua, Memberi kesempatan kepada anggota kelompok kerja atau musyawarah kerja untuk berbagi pengalaman serta saling memberikan bantuan dan umpan balik. Ketiga, meningkatkan pengetahuan dan keterampilan, serta mengadopsi pendekatan pembaharuan dalam pembelajaran yang lebih professional bagi peserta kelompok kerja atau musyawarah kerja. Keempat, Memberdayakan dan membantu anggota kelompok kerja dalam melaksanakan tugas-tugas pembelajaran di sekolah. Kelima, Mengubah budaya kerja anggota kelompok kerja atau musyawarah kerja (meningkatkan pengetahuan, kompetensi dan kinerja) dan mengembangkan profesionalisme guru melalui kegiatan-kegiatan pengembangan profesionalisme di tingkat KKG/MGMP. Keenam, Meningkatkan mutu proses pendidikan dan pembelajaran yang tercermin dari peningkatan hasil belajar peserta didik. Ketujuh, Meningkatkan kompetensi guru melalui kegiatan-kegiatan di tingkat KKG/MGMP (Departemen Pendidikan Nasional, 2008).

\section{Kompetensi Guru Mata Pelajaran}

Kompetensi bagi pendidik ditentukan oleh tingkat kepekaannya dari bobot potensi dasar dan kecenderungan yang dimiliki. Hal ini dikarenakan kompetensi 
merupakan wadah untuk memproses semua pandangan sebagai bahan untuk menjawab semua rangsangan yang datang darinya (Nur Khozin, 2019). Dalam UU No 14 tahun 2005 tentang Guru dan Dosen pada pasal 10 dijabarkan guru memiliki empat kompetensi yang terdiri dari kompetensi pedagogik, kompetensi kepribadian, kompetensi sosial, dan kompetensi profesional yang diperoleh melalui pendidikan profesi (UU Nomor 14, 2005). Adapun dalam Permendiknas Nomor 16 Tahun 2007 Tentang Standar Kualifikasi Akademik Dan Kompetensi Guru, Standar Kompetensi Guru Mata Pelajaran di SD/MI, SMP/MTs, SMA/MA, dan SMK/MAK yang dijabarkan pada kompetensi Inti guru dalam empat kompetensi guru sebagai berikut.

\section{a. Kompetensi Pedagogik}

1) Menguasai karakteristik peserta didik dari aspek fisik, moral, spiritual, sosial, kultural, emosional, dan intelektual.

2) Menguasai teori belajar dan prinsip-prinsip pembelajaran yang mendidik.

3) Mengembangkan kurikulum yang terkait dengan mata pelajaran yang diampu.

4) Menyelenggarakan pembelajaran yang mendidik.

5) Memanfaatkan teknologi informasi dan komunikasi untuk kepentingan pembelajaran.

6) Memfasilitasi pengembangan potensi peserta didik untuk mengaktualisasikan berbagai potensi yang dimiliki.

7) Berkomunikasi secara efektif, empatik, dan santun dengan peserta didik.

8) Menyelenggarakan penilaian dan evaluasi proses dan hasil belajar Memanfaatkan hasil penilaian dan evaluasi untuk kepentingan pembelajaran.

9) Memanfaatkan hasil penilaian dan evaluasi untuk kepentingan pembelajaran.

10) Melakukan tindakan reflektif untuk peningkatan kualitas pembelajaran.

\section{b. Kompetensi Kepribadian}

1) Bertindak sesuai dengan norma agama, hukum, sosial, dan kebudayaan nasional Indonesia

2) Menampilkan diri sebagai pribadi yang jujur, berakhlak mulia, dan teladan bagi peserta didik dan masyarakat.

3) Menampilkan diri sebagai pribadi yang mantap, stabil dewasa, arif, dan berwibawa.

4) Menunjukkan etos kerja, tanggung jawab yang tinggi, rasa bangga menjadi guru, dan rasa percaya diri.

5) Menjunjung tinggi kode etik profesi guru.

\section{c. Kompetensi Sosial}

1) Bersikap inklusif, bertindak objektif, serta tidak diskriminatif karena pertimbangan jenis kelamin, agama, ras, kondisi fisik, latar belakang keluarga, dan status sosial ekonomi.

2) Berkomunikasi secara efektif, empatik, dan santun dengan sesama pendidik, tenaga kependidikan, orang tua, dan masyarakat 
3) Beradaptasi di tempat bertugas di seluruh wilayah Republik Indonesia yang memiliki keragaman social budaya.

4) Berkomunikasi dengan komunitas profesi sendiri dan profesi lain secara lisan dan tulisan atau bentuk lain.

\section{d. Kompetensi Profesional}

1) Menguasai materi, struktur, konsep, dan pola pikir keilmuan yang mendukung mata pelajaran yang diampu.

2) Menguasai standar kompetensi dan kompetensi dasar mata pelajaran yang diampu.

3) Mengembangkan materi pembelajaran yang diampu secara kreatif.

4) Mengembangkan keprofesionalan secara berkelanjutan dengan melakukan tindakan reflektif.

5) Memanfaatkan teknologi informasi dan komunikasi untuk mengembangkan diri (Permendiknas nomor 16, 2007).

\section{Peran MGMP dalam meningkatkan kompetensi guru PAI}

Kompetensi menggambarkan kecakapan seseorang di bidang tertentu sebagai bekal dan menjadi tuntutan masyarakat terhadap kemampuannya untuk menjalankan pekerjaan tertentu (Husna, 2016). Menjadi berkompeten adalah keinginan bagi semua guru, akan tetapi untuk mencapainya dalam bekerja seorang guru harus dibekali dengan sejumlah pengalaman dan pelatihan. Selain itu, kompetensi juga merupakan salah satu kualifikasi guru yang terpenting. Bila kompetensi itu tidak ada pada diri seorang guru, maka guru yang bersangkutan tidak memiliki kompetensi dalam melaksanakan tugas guru di lembaga pendidikan formal. Sebab guru harus dapat memenuhi kompetensi yang diharapkan oleh masyarakat dan anak didik dalam melaksanakan pendidikan dan pembelajaran (Haly Manizar, 2017).

Pendidikan agama Islam adalah pendidikan dengan melalui ajaran-ajaran Islam, yaitu berupa bimbingan dan asuhan terhadap anak didik agar nantinya setelah selesai dari pendidikan ia dapat memahami, menghayati dan mengamalkan ajaran- ajaran agama Islam yang telah diyakininya secara menyeluruh, serta menjadikan agama Islam itu sebagai suatu pandangan hidupnya demi keselamatan dan kesejahteraan hidup di dunia maupun di akhirat kelak (Saddam Husein, 2018).

Dalam UU No 14 tahun 2005 tentang Guru dan Dosen pada pasal 10 dijabarkan guru memiliki empat kompetensi yang terdiri dari kompetensi pedagogik, kompetensi kepribadian, kompetensi sosial, dan kompetensi profesional yang diperoleh melalui pendidikan profesi (UU Nomor 14, 2005). Keempat kompetensi tersbut sangat berperan bagi para guru yang tergabung dalam forum MGMP. 
Bebrapa peran MGMP dalam meningkatkan kompetensi guru PAl yang dapat dikemukakan, meliputi:

a. Meningkatkan kompetensi guru melalui kompetensi pedagogik, kompetensi kepribadian, kompetensi sosial, dan kompetensi professional

b. Peningkatan kapasitas intelektual guru

c. Sebagai forum musyawarah untuk menemukan solusi dalam menghadapi tantangan dalam proses pembelajaran

d. Forum peningkatan profesi berkelanjutan.

Dengan demikian dapat disimpulkan, peran MGMP dalam meningkatkan kompetensi guru PAI, dalam operasionalnya memiliki peran yang sangat efektif dalam peningkatan kompetensi guru, selain sebagai sosok atau panutan bagi para peserta didik di sekolah, guru juga memainkan peran yang sangat besar dalam menentukan tinggi atau rendahnya mutu pendidikan.

\section{Kesimpulan}

MGMP merupakan suatu perkumpulan atau forum yang terdiri didalamnya adalah para guru satu mata pelajaran dari berbagai sekolah di suatu kota dengan tujuan saling melakukan tukar pendapat, pengalaman, komunikasi, belajar bersama dengan upaya mendapatkan perubahan dan pembaharuan dalam proses pembelajaran.

Dalam pelaksanaannya MGMP memiliki peran yang sangat efektif dalam peningkatan kompetensi guru, selain sebagai sosok atau panutan bagi para peserta didik di sekolah, guru juga memainkan peran yang sangat besar dalam menentukan tinggi atau rendahnya mutu pendidikan.

Adapun beberapa peran MGMP dalam meningkatkan kompetensi guru dianataranya sebagai forum, a. peningkatan kompetensi guru melalui kompetensi pedagogik, kompetensi kepribadian, kompetensi sosial, dan kompetensi professional, b. peningkatan kapasitas intelektual guru, c. sebagai forum musyawarah untuk menemukan solusi dalam menghadapi tantangan dalam proses pembelajaran, $d$. forum peningkatan profesi berkelanjutan.

\section{Daftar Pustaka}

[1] Anwar, Muhammad. 2018. Menjadi Guru Profesional, Pernada Media Group: Jakarta.

[2] Departemen Pendidikan Nasional, tahun 2008. Standar PengembanganKelompok Kerja Guru (KKG), Musyawarah Guru Mata Pelajaran (MGMP).

[3] Husna, F. (2016). PERAN MUSYAWARAH GURU MENINGKATKAN KOMPETENSI PROFESIONAL GURU PAI: Studi Kasus MGMP PAI SMP 


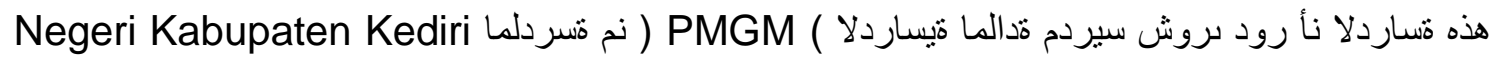

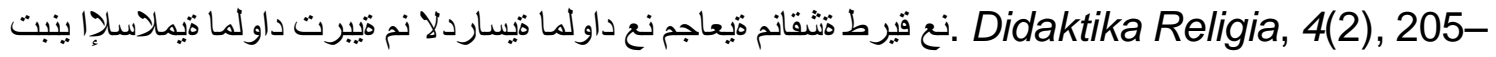
224.

[4] Firman. (2016). Peranan MGMP Dalam Meningkatkan Kinerja Guru Mata Pelajaran Pendidikan Agama Islam SMA di Kota Balikpapan. Sains Terapan, 2(1), 27-33.

[5] Husna, F. (2016). PERAN MUSYAWARAH GURU MENINGKATKAN KOMPETENSI PROFESIONAL GURU PAI: Studi Kasus MGMP PAI SMP

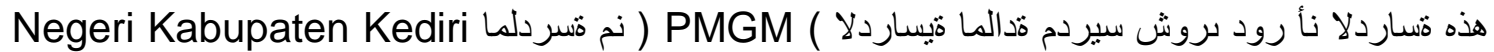

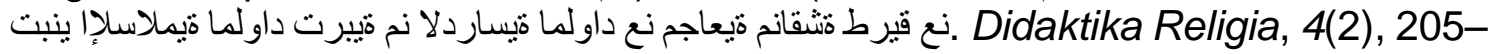
224.

[6] Manizar, E. (2017). Optimalisasi pendidikan agama islam di sekolah. Tadrib, 3(2), 251-277-113.

[7] Nur Khozin, S. J. L. R. (2019). Pemberdayaan Guru Pendidikan Agama Islam Melalui Peningkatan Kompetensi Guru Pada Tingkat Sekolah Dasar Di Waimital. al-Iltizam: Jurnal Pendidikan Agama Islam, 3(1), 28. https://doi.org/10.33477/alt.v3i1.415

[8] Saddam Husein, R. U. S. S. (2018). Urgensi Pembelajaran Al- Qur' an Hadist Terhadap, 3(1), 1-13.

[8] Maleong, Lexy. 2001. Penelitian Kualitatif, Bandung: Rineka Cipta.

[9] Mintarsih. 2012. Profesi Tenaga Kependidikan, Deepublish: Yogyakarta.

[10] Musafah, Jejen. 2015. Manajemen Pendidikan; Teori, Kebijakan dan Praktek, Kencana: Jakarta.

[11] Permendiknas Nomor 16 Tahun 2007 Tentang Standar Kualifikasi Akademik Dan Kompetensi Guru.

[12] Suyanto, 2013. Menjadi Guru Profesional; Strategi Meningkatkan Kualifikasi dan Kualitas Guru di Era Global, Penerbit Erlangga: Jakarta.

[13] UU Nomor 14 tahun 2005 tentang Guru dan Dosen. 